\title{
Toll-like receptor $7 / 8$ agonist resiquimod induces late preconditioning in neonatal cardiac myocytes
}

\author{
Yong-yi WANG, Sha LIU, Feng LIAN, Wen-gang YANG, Song XUE* \\ Department of Cardiovascular Surgery, RenJi Hospital of Shanghai Jiaotong University, Shanghai 200127, China
}

Aim: To investigate whether R-848 (resiquimod, toll-like receptor $7 / 8$ agonist) can induce late preconditioning in neonatal cardiac myocytes.

Methods: The protective effects of R-848 on neonatal myocytes against anoxia-reoxygenation-induced injury were tested, and intracellular reactive oxygen species (ROS) were determined. The protein synthesis inhibitor cyclohexamide (CH) and the ROS scavenger $\mathrm{N}$-acetylcysteine (NAC) were used in this model to test if new protein synthesis and oxidative stress were necessary for their cardioprotective effects. The activation of nuclear factor kappa B (NFKB) and hypoxia inducible factor 1 (HIF1) was investigated by electrophoretic mobility shift assays (EMSA), and inducible nitric oxide synthase (iNOS) was assessed by immunoblotting. After iNOS was downregulated by small interfering RNA (siRNA) transfection, the cardioprotective effect was reassessed.

Results: ROS were triggered soon after R-848 (0.01-1.0 $\mu \mathrm{g} / \mathrm{L})$ administration, however, the cardioprotective effect of which was induced $24 \mathrm{~h}$ later. This protection was abolished by $\mathrm{CH}$ or NAC pretreatment. NFKB and HIF1 activation and iNOS up-regulation were involved in this protective mechanism. The cardioprotective effect was also attenuated after iNOS was knocked down.

Conclusion: R-848 provided a cardioprotective effect through a late preconditioning mechanism via a ROS/NFKB-HIF1/iNOS-dependent pathway.

Keywords: toll like receptor; resiquimod; late preconditioning; anoxia-reoxygenation; reactive oxygen species; cardioprotection

Acta Pharmacologica Sinica (2011) 32: 565-572; doi: 10.1038/aps.2011.6; published online 25 Apr 2011

\section{Introduction}

TLRs (Toll-like receptors) are part of the innate immune system. They detect infections by highly conserved components of pathogens, such as some protein, lipid and nucleic structures. The stimulation of TLRs initiates the activation of an intracellular signaling network that promotes an inflammatory response via the release of proinflammatory cytokines ${ }^{[1]}$. Among the 10 TLRs identified in humans, TLR2 and TLR4, in addition to their critical role in mediating cardiac dysfunction in septic conditions, can also recognize endogenous ligands and may play an important role in modulating cardiomyocyte survival $^{[2-4]}$. LPS-induced preconditioning via TLR4 has been explored in heart, lung and brain ${ }^{[5]}$. Recently, it was reported that preconditioning by the TLR2 agonist Pam3CSK 4 reduces CXCL1-dependent leukocyte recruitment in murine myocardial ischemia/reperfusion injury ${ }^{[6]}$. The TLR9 ligand CpG oligodeoxynucleotide (ODN) can serve as a potent preconditioning stimulus and provide protection against ischemic brain injury $^{[7]}$. These recent studies indicate that multiple TLRs offer

\footnotetext{
* To whom correspondence should be addressed. E-mail xuesong64@gmail.com

Received 2010-10-11 Accepted 2011-01-16
}

promise as novel therapeutic targets for cell survival during ischemia/reperfusion injury in the heart.

TLR7 and TLR8, which are expressed intracellularly within one or more endosomal compartments, have been shown to mediate anti-viral responses by means of recognizing singlestranded RNA (ssRNA). Before ssRNA was identified as the natural ligand for TLR7 and TLR8, adenosine analogs such as imidazoquinolines were already used as agonists of TLR7 and TLR8. The imidazoquinoline imiquimod activates transcription factors like nuclear factor kappa B (NFKB) and results in a $\mathrm{T}$ helper (Th) 1-polarized immune response by the secretion of proinflammatory cytokines in human blood cells ${ }^{[8]}$. Therefore, imiquimod has been used as an anti-cancer treatment because of its ability to activate several immune pathways simultaneously, resulting in effective anti-tumor immunity. Resiquimod (R-848) is another imidazoquinoline that binds to both TLR7 and TLR8, resulting in an enhanced activity profile compared to imiquimod, and the use of R-848 is a promising strategy in TLR-based immunotherapy for acute myeloid leukemia ${ }^{[9]}$. Coxsackierus group B type 3 (CVB3) is considered the most common cause of viral myocarditis in humans, which triggers a cardiac inflammatory response mainly through a TLR7/ TLR8-dependent pathway ${ }^{[10]}$. Therefore, we deduced that 
R-848 could also initiate an inflammatory response and oxidative stress in cardiomyocytes. In this study, we demonstrate that R-848 can induce late preconditioning in cardiomyocytes.

NFKB is a redox-sensitive transcription factor. NFKB activation is involved in TLR7/8 downstream signaling through a MyD88-dependent pathway and is necessary in late preconditioning ${ }^{[11]}$. Recently, it was reported that both TLR4 and TLR7/ 8 induce accumulation/activation of HIF1a protein through a redox-dependent mechanism ${ }^{[12,13]}$, and activation of HIF1a is also involved in ischemic late preconditioning ${ }^{[14]}$. Therefore, the activation of NFKB and HIF1a in R-848-induced late preconditioning was determined, and the role of ROS in this activation and the down-regulated protein of these two transcription factors, inducible nitric oxide synthase (iNOS), were determined.

\section{Materials and methods}

Neonatal cardiomyocytes culture and anoxia-reoxygenation

Principles of laboratory animal care were followed. Neonatal cardiac myocytes were prepared from the hearts of 1-3 dayold Wistar rats (from Shanghai Laboratory Animal Center of the Chinese Academy of Sciences, Shanghai, China) as described previously ${ }^{[15]}$. Cells were plated at M199 (Invitrogen, Carlsbad, CA, USA) containing $10 \%$ fetal bovine serum (FBS, Invitrogen, Carlsbad, CA, USA) for $48 \mathrm{~h}$. Cells were incubated at $37{ }^{\circ} \mathrm{C}$ in an atmosphere with $5 \% \mathrm{CO}_{2}, 20 \% \mathrm{O}_{2}$ and $75 \% \mathrm{Ar}$ (standard gas mixture). Anoxia was attained with an airtight jar from which the $\mathrm{O}_{2}$ was flushed with a gas mixture containing $5 \% \mathrm{CO}_{2}$ and $95 \%$ Ar for $30 \mathrm{~min}$. Reoxygenation was realized by exchanging fresh medium and by its aeration with the standard gas mixture for $60 \mathrm{~min}$. R-848 (0.01 to $1.0 \mathrm{\mu g} / \mathrm{mL}$, Invivogen, San Diego, CA, USA) was dissolved in media and incubated with the cells for $24 \mathrm{~h}$ before anoxiareoxygenation. The cells were incubated with cyclohexamide $(\mathrm{CH}, 1.0 \mu \mathrm{mol} / \mathrm{L})$ for $10 \mathrm{~min}$ or $\mathrm{N}$-acetylcysteine (NAC, the ROS scavenger, $1 \mathrm{mmol} / \mathrm{L}$ ) for $1 \mathrm{~h}$ before the addition of R-848 $(0.1 \mu \mathrm{g} / \mathrm{mL})$ to the cultures.

\section{Cell viability determination}

Cell survival was evaluated by the ability to reduce MTT, an indication of metabolic activity. This viability assay was conducted in 96-well plates and read by spectrophotometry with a microplate reader (Bio-Tek Instruments, USA).

Measurement of lactate dehydrogenase (LDH), superoxide dismutase (SOD) activity and malondialdehyde (MDA) content in cells

Twenty-four hours after anoxia-reoxygenation, LDH was detected by a chromatometry assay kit, and SOD was measured by spectrophotometry using a commercially available detection kit (both kits were from Nanjing Jiancheng Biochemical Reagent CO, Nanjing, China) according to the manufacturer's instructions. The MDA content was determined using the thiobarbituric acid method with a commercial kit. The absorbance of each supernatant was measured at $532 \mathrm{~nm}$.
Measurement of the rate of protein synthesis (incorporation of $\left[{ }^{3} \mathrm{H}\right]$ leucine)

Cells in the presence of $\left[{ }^{3} \mathrm{H}\right]$ leucine were collected $2 \mathrm{~h}$ after stimulation with R-848 (or/and $\mathrm{CH}$ ), washed with PBS and precipitated with $10 \%$ trichloroacetic acid (TCA) at $4^{\circ} \mathrm{C}$ for $1 \mathrm{~h}$. The precipitate was solubilized in $\mathrm{NaOH} 0.15 \mathrm{~mol} / \mathrm{L}$. The cell lysate was vacuum-filtrated onto the glass-fiber filter. The filter was dried after being washed with 10\% TCA and 100\% ethanol. The radioactivity of the incorporated $\left[{ }^{3} \mathrm{H}\right]$ leucine was measured with a scintillation counter.

\section{Measurement of intracellular ROS}

Equal numbers of cells (10000/well in 96-well plates in Hanks Balanced Salt Solution) were treated with $10 \mu \mathrm{mol} / \mathrm{L}$ 2,7-dichlorofluoroscein diacetate (DCF-DA) for $3 \mathrm{~h}$. Cells were washed with phosphate-buffered saline and treated with 0.1 $\mu \mathrm{g} / \mathrm{mL}$ R-848 during different time intervals. DCF-DA penetrates into viable cells, and inside the cells, it is converted to DCF, which later reacts with ROS and fluorescence. At the indicated time intervals, the intensity of the fluorescence was measured at an excitation wavelength of $485 \mathrm{~nm}$ and an emission wavelength of $527 \mathrm{~nm}$ and is expressed as percent of control fluorescence.

\section{Transfer of iNOS siRNA to cardiomyocytes and R-848 treatment} iNOS siRNA was chemically synthesized by Shanghai GeneChem Co, Ltd. The targeted sequence resides within the open reading frame of the rat iNOS gene (accession: NM_012611), 898 nucleotides downstream of the start codon. The double strands of siRNA for rat iNOS were taken from published sequences ${ }^{[16]}$. Cells were transfected with a siRNA targeted for rat iNOS using Lipofectamine 2000 (Invitrogen). A siRNA consisting of a scrambled sequence of similar length was transfected as a control siRNA. Cells that experienced the same transfection procedure without any siRNA transfection were considered to be the sham-treated group. One day before transfection, cells were plated in $500 \mu \mathrm{L}$ of growth medium without antibiotics such that they were $25 \%-45 \%$ confluent at the time of transfection. The transfected cells were cultured in M199 containing 10\% fetal calf serum for $72 \mathrm{~h}$ after transfection. After $72 \mathrm{~h}$ of siRNA transfection, both the transfected and non-transfected (sham) cells were cultured for $1 \mathrm{~d}$ in serum-free M199 media to arrest growth before R-848 treatment. R-848 was added at a concentration of $0.1 \mu \mathrm{g} / \mathrm{mL}$. Cells were collected for NFKB, HIF1a, and iNOS examination $24 \mathrm{~h}$ after R-848 treatment.

\section{RNA extraction and reverse transcription real time PCR}

Total RNA was isolated from cell pellets using a Qiagen RNeasy minikit (Qiagen, Valencia, CA, USA). First-strand cDNA synthesis was performed for each RNA sample using Superscript II RT Kit (GIBCO BRL, Life Technologies). iNOS mRNA expression was determined by real time PCR using SYBR Premix Ex TaqTM (Takara, Tokyo, Japan). Nucleotide sequences of specific primers for iNOS were designed as described previously ${ }^{[16]}$. A two-step PCR program was per- 
formed. Data were collected and quantitatively analyzed on an ABI PRISM 7900HT sequence detection system (Applied Biosystems, Warrington, Cheshire, UK). The $18 \mathrm{~S}$ rRNA gene was used as an endogenous control to normalize the differences in the amount of total RNA in each sample. All values were expressed as fold increase or decrease relative to the expression of $18 \mathrm{~S}$ rRNA. The mean value of the replicates for each sample was calculated and expressed as cycle threshold (Ct: cycle number at which each PCR reaction reaches a predetermined fluorescence threshold, set within the linear range of all reactions). The amount of gene expression was then calculated as the difference $(\Delta \mathrm{Ct})$ between the $\mathrm{Ct}$ value of the sample for the target gene and the mean $\mathrm{Ct}$ value of that sample for the endogenous control (18S rRNA). Relative expression was calculated as the difference $(\Delta \Delta \mathrm{Ct})$ between the $\Delta \mathrm{Ct}$ values of the test sample and of the control sample. Relative expressions of genes of interest were calculated and expressed as $2^{-\Delta \Delta \mathrm{Ct}[17]}$.

\section{Preparation of protein extracts}

The method by Andrews and Faller ${ }^{[18]}$ was adopted to get the nuclear extracts. Briefly, the cells were washed with cold PBS and homogenized with a cell scraper. The pellets were collected after centrifugation. The cell pellets were then resuspended in buffer $\mathrm{B}(10 \mathrm{mmol} / \mathrm{L}$ HEPES-KOH $\mathrm{pH} 7.9,1.5$ $\mathrm{mmol} / \mathrm{L} \mathrm{MgCl}_{2}, 10 \mathrm{mmol} / \mathrm{L} \mathrm{KCl}, 1 \mathrm{mmol} / \mathrm{L} \mathrm{DTT}, 1 \mathrm{mmol} / \mathrm{L}$ PMSF, $10 \mu \mathrm{g} / \mathrm{mL}$ apotinin, $10 \mu \mathrm{g} / \mathrm{mL}$ pepstatin, $10 \mu \mathrm{g} / \mathrm{mL}$ leupeptin and $0.1 \% \mathrm{NP}-40$ ) and vortexed at $4{ }^{\circ} \mathrm{C}$ for $10 \mathrm{~s}$. The tube was centrifuged to re-obtain the pellet. The pellets were resuspended in buffer $\mathrm{C}(20 \mathrm{mmol} / \mathrm{L}$ HEPES-KOH pH 7.9, 1.5 $\mathrm{mmol} / \mathrm{L} \mathrm{MgCl}_{2}, 400 \mathrm{mmol} / \mathrm{L} \mathrm{NaCl}, 0.2 \mathrm{mmol} / \mathrm{L}$ EDTA, 25\% glycerol, $1 \mathrm{mmol} / \mathrm{L}$ DTT, $1 \mathrm{mmol} / \mathrm{L}$ PMSF, $2 \mu \mathrm{g} / \mathrm{mL}$ aprotinin and $10 \mu \mathrm{g} / \mathrm{mL}$ leupeptin) and gently shaken at $4{ }^{\circ} \mathrm{C}$ for $30 \mathrm{~min}$. Nuclear protein extracts were obtained by centrifugation at 12000 revolutions per minute for $15 \mathrm{~min}$. All the extracts were stored at $-80^{\circ} \mathrm{C}$.

\section{Electrophoretic mobility shift assay (EMSA)}

Nuclear extracts $(20 \mu \mathrm{g})$ were pre-incubated for $10 \mathrm{~min}$ in binding buffer $(1 \mu \mathrm{g}$ poly dI-dC, $10 \mathrm{mmol} / \mathrm{L}$ Tris- $\mathrm{HCl} \mathrm{pH} 7.5$, $50 \mathrm{mmol} / \mathrm{L} \mathrm{NaCl}, 1 \mathrm{mmol} / \mathrm{L}$ EDTA, 5\% Glycerol, $1 \mathrm{mmol} / \mathrm{L}$ DTT, $1 \mu \mathrm{g} / \mu \mathrm{L}$ BSA) on ice, followed by $30 \mathrm{~min}$ of incubation at room temperature with $1 \times 10^{5} \mathrm{dpm}$ (about $0.5 \mathrm{ng}$ ) of a $\mathrm{Y}^{-}{ }^{32} \mathrm{P}-$ labeled probe (Amersham Biosciences, Sunnyvale, CA, USA) containing the NFKB binding site 5'-AGTTGAGGGGACTTTCCCAGGC-3' or the HIF1a binding site 5'-AGCGTAATGCGT-
GCCTCAGGA-3' (both from Santa Cruz Biotechnology, Santa Cruz, CA, USA). DNA-protein complexes were run on a $6 \%$ polyacrylamide gel. For supershift analysis, anti-p65, anti-p50 or anti HIF1a was incubated in the binding buffer for $15 \mathrm{~min}$ prior to adding the radiolabeled probe. Unlabeled probes for NFkB and HIF1a, both in 50× excess, were used as competition assays.

\section{Western blotting analysis}

The cytoplasmic extracts $(20 \mu \mathrm{g})$ were mixed with buffer and boiled for $5 \mathrm{~min}$. Proteins were electrophoresed followed by transfer to precoated nitrocellulose membranes. Membranes were blocked with $3 \%$ bovine serum albumin for $2 \mathrm{~h}$, then incubated overnight with primary mouse antibodies against iNOS (Santa Cruz Biotechnology, Santa Cruz, CA, USA) or $\beta$-actin. Membranes were incubated with a primary antibody and were then exposed to peroxidase-conjugated anti-mouse IgG for $2 \mathrm{~h}$. Proteins were visualized by enhanced chemiluminescence. Bands were scanned into Adobe Photoshop 5.0 and relative absorbency was calculated in Tina 2.0 software as a semi-quantitative method. The iNOS quantitative relative expression (RE) was calculated by comparison to $\beta$-actin.

\section{Statistical analysis}

The software SPSS13.0 was used to analyze the experimental data. Values are presented as mean \pm SD. All data were analyzed by one-way ANOVA. Statistical significance was defined as a $P$ value less than 0.05 .

\section{Results}

Effect of R-848 on neonatal cardiomyocyte viability, LDH, SOD activity and MDA content

We first assessed the effect of R-848 on cardiomyocytes. Cardiomyocytes were examined by testing their viability, LDH, SOD activity and MDA content. As shown in Table 1, the cell viability increased after being treated with R-848 $(P<0.05)$, compared to the control group. In addition, pretreatment of cell cultures with R-848 (0.01 to $1.0 \mu \mathrm{g} / \mathrm{mL})$ for $24 \mathrm{~h}$ before exposure to the anoxia-reoxygenation process significantly reduced cell death. The effect of R-848 was maximally protective at $0.1 \mu \mathrm{g} / \mathrm{mL}$.

Further, the integrity of cell membranes or necrosis is estimated by LDH release into the media in response to oxidant burden. The toxicity caused by ROS was normally accompanied by an increase of lipid peroxides and was determined by MDA content and SOD activity. As shown in Table 1, there

Table 1. Cardioprotective effects of R-848 $24 \mathrm{~h}$ after anoxia-reoxygenation injury assessed by cell viability, LDH activity, MDA content, and SOD activity. Mean \pm SD. ${ }^{\mathrm{b}} P<0.05,{ }^{\mathrm{c}} P<0.01$ vs control group.

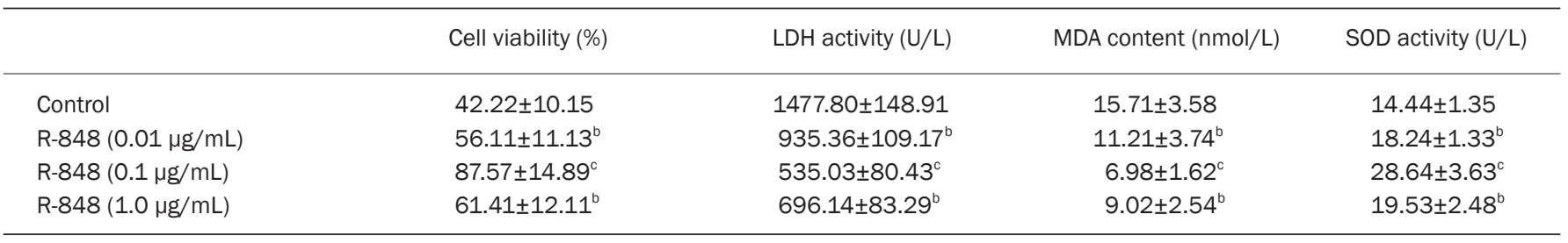


was an increase in SOD activity, a decrease in LDH leakage and MDA production after R-848 pretreatment. There was a maximally protective effect of R-848 at the concentration of $0.1 \mu \mathrm{g} / \mathrm{mL}$. Based on these dose response results, all further studies were performed with $0.1 \mathrm{\mu g} / \mathrm{mL}$ R-848. Collectively, these results indicate that pretreatment of cells with R-848 $24 \mathrm{~h}$ before anoxia-reoxygenation provides marked protection.

\section{R-848 induced RoS expression}

As shown in Figure 1, $0.1 \mu \mathrm{g} / \mathrm{mL}$ R-848 increased ROS in a time-dependent manner. The increase in ROS after $30 \mathrm{~min}$ was followed by a slow increase until $4 \mathrm{~h}$. ROS decreased almost to their original levels by $24 \mathrm{~h}$.

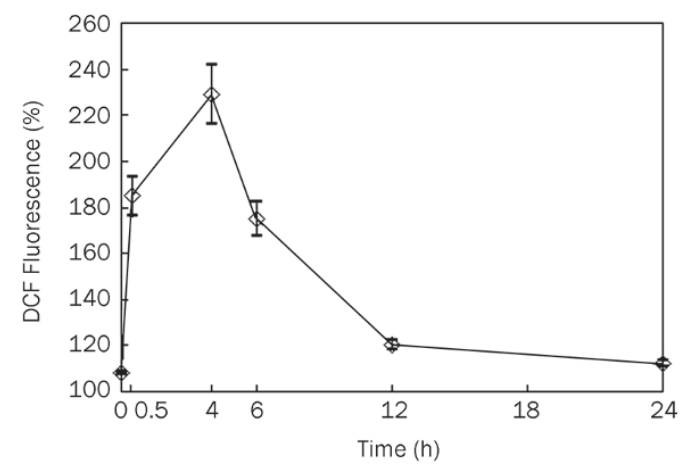

Figure 1. Measurement of intracellular ROS. Time course of induction of ROS by R-848 in cardiac myocytes. Cells were incubated with 0.1 $\mu \mathrm{g} / \mathrm{mL} \mathrm{R}-848$. Fluorescence was measured at different time intervals as described in Materials and methods. The values expressed as percent of control fluorescence mean \pm SD of 8 wells and the figure is a representative from three experiments performed independently.

Effect of $\mathrm{CH}$ or NAC pretreatment in cell viability, LDH, SOD activity and MDA content after R-848 administration

As shown in Table 2, the toxic action of $\mathrm{CH}$ can be ignored because the anoxia-reoxygenation injury determined by cell viability, LDH activity, MDA content and SOD activity was similar between the control and $\mathrm{CH}$ groups. The NAC group did not present better results compared to the control group. NAC was administered $24 \mathrm{~h}$ before anoxia-reoxygenation, and it is possible that its activity as a ROS scavenger was abolished $24 \mathrm{~h}$ later. Otherwise, the concentration used in this study was minor compared to the intense oxidative stress induced by anoxia-reoxygenation. The cardioprotective effect of R-848 was completely blocked after simultaneous $\mathrm{CH}$ pretreatment. Compared to the R-848 group, protein synthesis and the cardioprotective effect were also completely blocked after simultaneous NAC pretreatment. A ROS-dependent pathway was apparent in protein synthesis.

\section{Activation of NFKB and HIF1 $\alpha$ after R-848 administration, which was abolished after NAC pretreatment}

We have demonstrated that the R-848-induced cardioprotective effect was completely blocked after NAC administration. Here, we have examined the activation of NFkB and HIF1. As shown in Figure 2A, we found that NFkB was activated by $\mathrm{R}-848$, as evidenced by the retardation in the mobility of the DNA probe containing the NFKB motif R-848 groups. Conversely, low activation of NFKB was noted in the R-848+NAC group. The same status was seen in EMSA of HIF1 (Figure $2 B)$. Therefore, we deduced that R-848 can activate these two transcription factors in a redox-dependent manner. The identity of the proteins bound to the probe was determined by supershift analysis. The antibody specific for the p65 subunit, the p50 subunit, or both subunits of the NFKB heretodimer in particular caused retardation of the mobility of the DNA probe (Figure 2C). The antibody specific for HIF1a also slowed probe mobility (Figure 2D). The supershift assay demonstrated the bands as NFKB and HIF1, respectively. Competitive inhibition with the cold probe for NFKB and HIF1a extinguished the bands. The competition assay further identified the bands as NFKB and HIF1, respectively.

iNOS protein was elevated after R-848 administration, and this elevation was attenuated after NAC pretreatment

Detection of iNOS in cytoplasmic extracts by Western blotting showed that iNOS protein expression was robustly elevated after R-848 treatment; however, this elevation was abolished after NAC pretreatment. As shown in Figure 3, the RE in the R-848 group $(0.810 \pm 0.057)$ was higher than the control group $(0.204 \pm 0.019)$ and the R-848+NAC group $(0.221 \pm 0.013), P<0.01$. This agrees with the above result that protein synthesis was ROS-dependent.

Table 2. Effect of $\mathrm{CH}$ or NAC pretreatment in cell viability, LDH, SOD activity and MDA content after R-848 administration. ${ }^{\circ} P<0.01$ vs control group.

\begin{tabular}{|c|c|c|c|c|c|}
\hline & $\begin{array}{l}{\left[{ }^{3} \mathrm{H}\right] \text { leu incorporation }} \\
\quad(\mathrm{cpm} / \text { well })\end{array}$ & Cell viability (\%) & LDH activity (U/L) & $\begin{array}{l}\text { MDA content } \\
(\mathrm{nmol} / \mathrm{L})\end{array}$ & $\begin{array}{l}\text { SOD activity } \\
(\mathrm{U} / \mathrm{L})\end{array}$ \\
\hline Control & $2070 \pm 114$ & $39.13 \pm 8.14$ & $1601.23 \pm 147.86$ & $17.26 \pm 3.97$ & $14.14 \pm 1.39$ \\
\hline $\mathrm{CH}$ & $2101 \pm 116$ & $39.07 \pm 7.76$ & $1589.65 \pm 163.85$ & $16.82 \pm 3.89$ & $14.58 \pm 1.37$ \\
\hline $\mathrm{R}-848$ & $3191 \pm 249^{c}$ & $82.32 \pm 16.45^{c}$ & $540.21 \pm 71.17^{\circ}$ & $5.38 \pm 1.78^{c}$ & $24.69 \pm 3.61^{c}$ \\
\hline $\mathrm{CH}+\mathrm{R}-848$ & $1946 \pm 97$ & $40.40 \pm 8.68$ & $1592.32 \pm 156.87$ & $15.89 \pm 3.27$ & $15.89 \pm 2.49$ \\
\hline
\end{tabular}


A

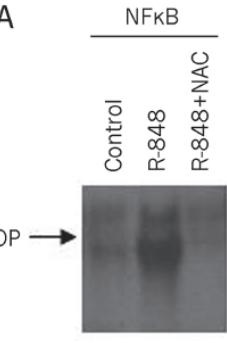

B

HIF1

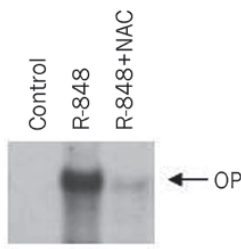

C

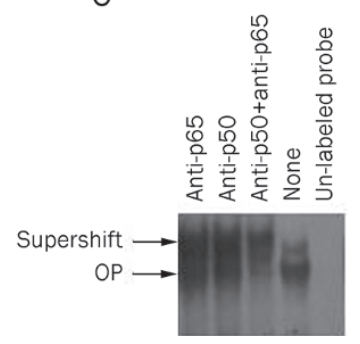

D

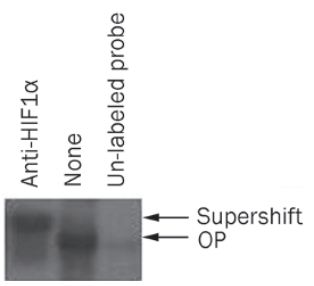

Figure 2. Identification of NFKB and HIF1 complexes in nuclear extracts by electrophoretic mobility shift assay (EMSA), supershift assay and competitive assay. Nuclear protein was extracted and analyzed by EMSA. Arrows denote oligonucleotide/protein complex. (A) Activation of NFKB. (B) Activation of HIF1. (C) To test the specificity of NFkB detection, nuclear extracts without preincubated with any antibody or competitive probe (none), or nuclear extracts were preincubated with an antibody against p65 subunit, an antibody against p50 subunit, antibodies against p65 plus p50 subunit, or 50 fold excess of un-labeled NFkB probe. (D) To test the specificity of HIF1 detection, nuclear extracts without preincubated with any antibody or competitive probe (none), or nuclear extracts were preincubated with an antibody against HIF1 $\alpha$ subunit, or 50 fold excess of un-labeled HIF1 probe. EMSAs are representative of one experiment done in triplicate. OP, oligonucleotide/protein complex.

A
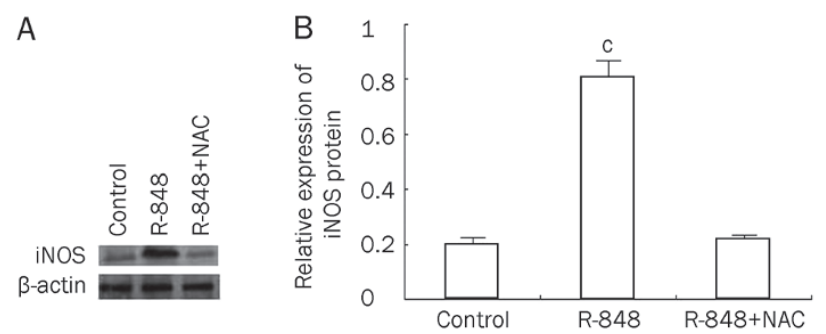

Figure 3. Immunoblotting analysis of iNOS after R-848 or R-848+NAC disposal. Detection of iNOS in cytoplasmic extracts was conducted $24 \mathrm{~h}$ after R-848 treatment. iNOS quantitative relative expression (RE) was calculated by comparing to $\beta$-actin. (A) iNOS protein in cytoplasmic extracts among groups. (B) Relative expression (RE) level of iNOS protein among groups. Results are expressed as mean $\pm \mathrm{SD}$; Data are the mean of three separate experiments. ${ }^{c} P<0.01$ vs control.

RNAi knocked down iNOS mRNA and protein expression in R-848-treated cells and abolished the cardioprotective effects

To investigate the effect of iNOS RNAi in R-848 treated cells,

all groups were treated with R-848 after RNAi. As shown in Figure 4, iNOS siRNA produced significant reductions in iNOS mRNA compared to the sham-treated and control groups. The relative iNOS mRNA expression in the control siRNA group $(1.0 \pm 0.03)$ and the sham transfection group $(0.97 \pm 0.04)$ was higher than the iNOS RNAi group (0.023 \pm 0.003$), P<0.01$. This indicates that RNAi knocked down the mRNA expression of iNOS effectively. Data are expressed as fold increase or decrease relative to the rRNA expression of the housekeeping gene $18 \mathrm{~S}$.

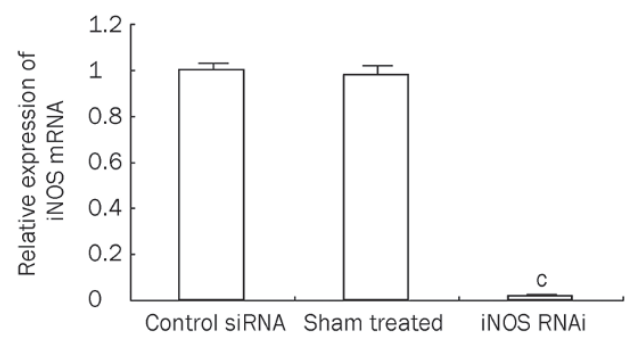

Figure 4. RNAi knocks down the mRNA expression of iNOS in R-848 treated cells. Detection of iNOS mRNA expression was conducted by real time PCR $24 \mathrm{~h}$ after R-848 treatment. The amount of gene expression was calculated as the difference $(\Delta \mathrm{Ct})$ between the $\mathrm{Ct}$ value of the sample for the target gene and the mean Ct value of that sample for the endogenous control (18S rRNA). Relative expression was calculated as the difference $(\Delta \Delta \mathrm{Ct})$ between the $\Delta \mathrm{Ct}$ values of the test sample and of the control sample. Relative expression of genes of interest was calculated and expressed as $2^{-\Delta \Delta c t}$. ${ }^{c} P<0.01$.

In comparison to the result of real time PCR, Western blotting for iNOS confirmed a similar pattern of expression of the protein, such that the level of iNOS was decreased with RNAi treatment. As shown in Figure 5, the RE in the sham transfection $(0.77 \pm 0.047)$ and control siRNA groups $(0.79 \pm 0.051)$ was higher than the iNOS RNAi group $(0.33 \pm 0.013), P<0.01$. This demonstrates that RNAi knocked down the expression of
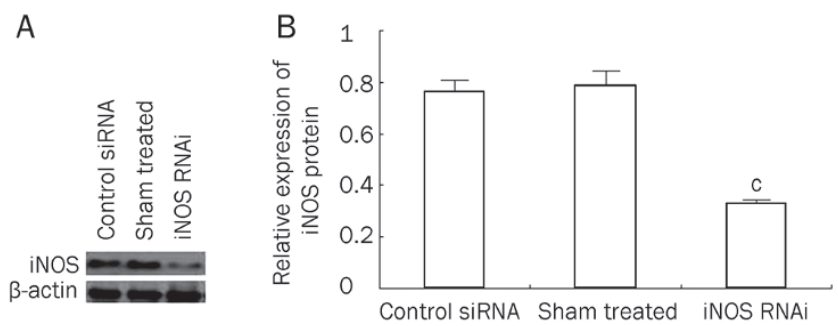

Figure 5. Immunoblotting analysis of iNOS after RNAi treatments. After $72 \mathrm{~h}$ of siRNA transfection, all cells were cultured for $24 \mathrm{~h}$ in serum-free media to arrest growth. Then, detection of iNOS in cytoplasmic extracts was conducted $24 \mathrm{~h}$ after R-848 treatment. iNOS quantitative relative expression (RE) was calculated by comparing to $\beta$-actin. (A) iNOS protein in cytoplasmic extracts among groups. (B) Relative expression (RE) level of iNOS protein among groups. Results are expressed as mean $\pm S D$; data are the mean of three separate experiments. ${ }^{\circ} P<0.01$. 
iNOS protein in R-848-treated cells.

After iNOS down-regulation by siRNA, we next examined its cardioprotective effect following anoxia-reoxygenation. As shown in Table 3, we found that the cardioprotective effect was completely lost in the iNOS siRNA group compared to the other two groups.

\section{Discussion}

Experimentally preconditioning with various TLR agonists has been proven to successfully attenuate ischemic damage through various protective mechanisms ${ }^{[19]}$. In this study, an endogenous protective mechanism called late preconditioning was explored in TLR7/8 agonist, R-848-induced cardioprotection. Late preconditioning induced ischemically or pharmacologically becomes apparent 12-24 h later and lasts 3-4 d. Nonlethal cellular stress causes the release of chemical signals such as nitric oxide (NO), ROS and adenosine, which serve as triggers for late preconditioning. Many pharmacological agents including proinflammatory cytokines and nitric oxide donors can also induce late preconditioning. This preconditioning is followed by a complex signal transduction cascade involving protein kinase $\mathrm{C} \varepsilon(\mathrm{PKC} \varepsilon)$, protein tyrosine kinase (PTK), mitogen-activated protein kinase (MAPKs) and as of yet unknown kinases. The recruitment of these kinases leads to the activation of NFKB and AP-1 and other transcription factors, which results in the synthesis of multiple cardioprotective proteins that serve as effectors $24 \mathrm{~h}$ after the preconditioning stimulus. The effector proteins include inducible nitric oxide synthase (iNOS), manganese superoxide dismutase (MnSOD), heat shock proteins (HSPs) and activated ion channels ${ }^{[20]}$. In summary, late preconditioning depends on genomic reprogramming, and effector protein synthesis is necessary for the development of late preconditioning ${ }^{[21]}$. Effector protein synthesis is required for the late preconditioning effects observed in vitro after pretreatment of rats with norepinephrine ${ }^{[22]}$ or cells with osteopontin ${ }^{[23]}$ and in vivo after six short ischemia-reperfusion cycles in rabbits $^{[21]}$. In our study, the cardioprotective effect of $\mathrm{R}-848$ was blocked after $\mathrm{CH}$ intervention.

Cardiomyocytes exposed to anoxia-reoxygenation in vitro experience a pathophysiological process similar to myocardial ischemia-reperfusion injury in vivo, and this is a wellestablished model. Pretreatment of cell cultures with R-848 for $24 \mathrm{~h}$ before exposure to anoxia-reoxygenation significantly increased cell survival and reduced LDH, SOD activity and MDA content. This demonstrates a prolonged cardioprotective effect that becomes apparent $24 \mathrm{~h}$ later, after pharmaco- logic disposal.

As mentioned above, the R-848-induced protective effect was obvious $24 \mathrm{~h}$ after drug administration, and this effect was completely abolished after $\mathrm{CH}$ intervention. Therefore, we conclude that R-848-induced protection is achieved through a late preconditioning mechanism.

ROS plays a crucial role in the pathogenesis of myocardial ischemia-reperfusion injury giving rise to the "death signal" resulting in apoptotic cell death, leading to an infarcted heart. However, the cardioprotective abilities of preconditioning are completely abolished when the heart is perfused with NAC to scavenge ROS, suggesting that redox signaling plays a crucial role in generating survival signals during myocardial adaptation to ischemia. Therefore, ROS can function as signaling molecules in mediating survival signals ${ }^{[24]}$. The transduction signature of ischemic preconditioning is comprised of the activation of PKC via G-protein-coupled receptors and endogenously released oxygen radicals. Protection and PKC activation can be mimicked by extracellular generation or application of $\operatorname{ROS}^{[25]}$. Limited oxidative stress can actually induce preconditioning $^{[26]}$. Recently, it was reported that when TLR4 is activated, ROS are produced and inflammatory cytokines and nitric oxide are released ${ }^{[27]}$. The universal adaptor MyD88 is also associated with TLR7/8, and is known to promote the generation of ROS. A signaling pathway including Burton's tyrosine kinase (Btk), PLC-1ץ, DAG, PI, intracellular $\mathrm{Ca}^{2+}$, $\mathrm{PKCa} / \beta$ and Nox was demonstrated to generate subsequent ROS after R-848 administration in THP-1 human myeloid marophages $^{[13]}$. In our study, the generation of ROS after R-848 administration in cardiomyocytes was demonstrated directly by ROS measurement and indirectly by NAC administration. Because NAC pretreatment blocked protein synthesis and abolished the delayed protective effect completely, we deduce that generated ROS play important roles in transmitting survival signals in R-848-induced late preconditioning.

MyD88 is a universal adaptor that activates the inflammatory pathway in TLR7/8 signaling. In the MyD88-dependent pathway, transforming growth factor $\beta$-activated kinase 1 (TAK1), a mitogen-activated protein kinase (MAPK) kinase kinase (MAPKKK), activates two downstream pathways involving the inhibitor of $\mathrm{NF}_{\mathrm{KB}}$ kinase (IKK) complex and the MAPK family, p38 and c-Jun $\mathrm{NH}_{2}$-terminal kinase. The IKK complex catalyzes the phosphorylation and proteolytic degradation of IKB proteins, which leads to the translocation of NFKB to the nucleus and its subsequent binding to its cognate DNA sequence on responsive genes ${ }^{[1]}$. Activated NFKB is

Table 3. Cardioprotective effects $24 \mathrm{~h}$ after anoxia-reoxygenation injury assessed by cell viability, LDH activity, MDA content, SOD activity after iNOS siRNA transfection disposal. ${ }^{c} P<0.01$ vs control siRNA group.

\begin{tabular}{|c|c|c|c|c|}
\hline & Cell viability (\%) & LDH activity (U/L) & MDA content (nmol/L) & SOD activity (U/L) \\
\hline Control siRNA & $83.51 \pm 13.09$ & $516.13 \pm 83.85$ & $6.68 \pm 1.47$ & $28.80 \pm 3.72$ \\
\hline Sham treated & $90.53 \pm 14.91$ & $527.04 \pm 85.69$ & $6.55 \pm 1.71$ & $27.76 \pm 3.57$ \\
\hline iNOS RNAi & $46.60 \pm 11.19^{c}$ & $1502.85 \pm 139.89^{c}$ & $15.37 \pm 3.10^{c}$ & $15.58 \pm 1.68^{\circ}$ \\
\hline
\end{tabular}


essential for ischemia late preconditioning. Recently, Nicholas SA et al demonstrated that ligand-induced activation of TLR7/ 8 results in the accumulation of HIF1a protein in THP-1 human myeloid macrophages via redox- and reactive nitrogen species-dependent mechanisms ${ }^{[12]}$. This activation is important for the support of cell survival as it protects the effector cells against the depletion of ATP and thus contributes to the production of proinflammatory cytokines ${ }^{[13,14]}$. In our study, activated HIF1 was also demonstrated. Briefly, receptor tyrosine kinases play an important role in redox signaling via autophosphorylation of tyrosines along their own intracellular tails. We conclude that the mitogenic signals were mediated through the generation of ROS activate transcription factors including NFKB and HIF1a because the activation of NFKB and HIF1a was abolished after NAC pretreatment before R-848 administration.

Expression of HIF1a mRNA and protein is induced in the brains of neonatal rats following hypoxia, intraperitoneal injection of cobalt chloride or desferrioxamine, and this up-regulation is associated with protection against cerebral infarction following hypoxia and ischemia ${ }^{[28]}$. HIF1a expression is also likely to be involved in cardiac preconditioning because NOS2 expression is essential for late preconditioning, and an intact HIF1 DNA binding site in the NOS2 promoter is required for its transcriptional induction in hypoxic myocardial cells ${ }^{[29]}$. Previous reports demonstrated that HIF1 interacts with the iNOS promoter directly in myocardial extracts after intermittent hypoxic preconditioning by using chromatin immunoprecipitation assay (CHIP) analysis ${ }^{[30]}$. Moreover, other studies have indirectly observed the regulation of the iNOS by HIF1 in the heart with the use of knockout iNOS mice ${ }^{[31]}$. Besides HIF1 regulation, NFkB regulation of iNOS expression was also involved in anisomycin-elicited late preconditioning in the heart $^{[32]}$. NFKB and HIF1a are the major modulators of iNOS gene expression. Therefore, iNOS protein expression in R-848treated myocytes was determined. We demonstrated that iNOS protein expression elevated. However, this elevation was attenuated after NAC pretreatment. Because ROS-dependent activation of NFKB and HIF1a was proven in a previous experiment, we conclude that iNOS gene expression occurs through a ROS/ NFkB-HIF1a-dependent pathway.

There is substantial evidence that iNOS plays an obligatory role in $\mathrm{NO}$ generation in late preconditioning by acting as a mediator or an effector protein of preconditioning ${ }^{[20,33]}$. NO generated from iNOS may open mitochondrial ATP-sensitive $\mathrm{K}^{+}$channels, which have been considered to be end-effectors for myocardial protection ${ }^{[34]}$. In our study, R-848-induced protection was also abolished after iNOS knocked down.

In summary, a ROS/ NFKB-HIF1a/ iNOS-dependent pathway was demonstrated in R-848-induced late preconditioning, and this result offers promise for the application of R-848 as a cardioprotectant in anoxia-reoxygenation (ischemia-reperfusion) injury. Recently, two classes of single-stranded TLR7/8 and TLR8 RNA agonists with diverse target cell and species specificities and immune response profiles were reported ${ }^{[35]}$. Goodchild et al demonstrated a model of TLR7/8 activation by siRNAs, in which the two strands are denatured in the endosome, and single-stranded, U-rich RNA species activate TLR7 $/ 8^{[36]}$. A follow-up study is warranted to determine whether these highly specific RNA species already identified are also useful in the development of pharmacological agents with cardioprotective applications.

\section{Acknowledgements}

The study was supported by the RenJi Hospital Fund for Scientific Research for Selecting and Training Outstanding Young Teachers in Shanghai Universities (jdy09032). We thank Dr Xiao-bing ZHAO of Ohio State University for his help in revising this manuscript.

\section{Author contribution}

Yong-yi WANG and Song XUE designed the research; Yongyi WANG and Wen-gang YANG performed the research; Sha LIU and Feng LIAN analyzed the data; Yong-yi WANG and Song XUE wrote the paper.

\section{References}

1 Kawai T, Akira S. TLR signaling. Semin Immunol 2007; 19: 24-32.

2 Chao W. Toll-like receptor signaling: a critical modulator of cell survival and ischemic injury in the heart. Am J Physiol Heart Circ Physiol 2009; 296: H1-12.

3 Timmers L, Sluijter JP, van Keulen JK, Hoefer IE, Nederhoff MG, Goumans MJ, et al. Toll-like receptor 4 mediates maladaptive left ventricular remodeling and impairs cardiac function after myocardial infarction. Circ Res 2008; 102: 257-64.

4 Zhu X, Bagchi A, Zhao H, Kirschning CJ, Hajjar RJ, Chao W, et al. Toll-like receptor 2 activation by bacterial peptidoglycan-associated lipoprotein activates cardiomyocyte inflammation and contractile dysfunction. Crit Care Med 2007; 35: 886-92.

5 Zhu X, Zhao H, Graveline AR, Buys ES, Schmidt U, Bloch KD, et al. MyD88 and NOS2 are essential for toll-like receptor 4-mediated survival effect in cardiomyocytes. Am J Physiol Heart Circ Physiol 2006; 291: H1900-9.

6 Mersmann J, Berkels R, Zacharowski P, Tran N, Koch A, lekushi K, et al. Preconditioning by toll-like receptor 2 agonist Pam3CSK 4 reduces CXCL1-dependent leukocyte recruitment in murine myocardial ischemia/reperfusion injury. Crit Care Med 2010; 38: 903-9.

7 Stevens SL, Ciesielski TM, Marsh BJ, Yang T, Homen DS, Boule JL, et al. Toll-like receptor 9: a new target of ischemic preconditioning in the brain. J Cereb Blood Flow Metab 2008; 28: 1040-7.

8 Wagner TL, Ahonen CL, Couture AM, Gibson SJ, Miller RL, Smith $\mathrm{RM}$, et al. Modulation of $\mathrm{TH} 1$ and $\mathrm{TH} 2$ cytokine production with the immune response modifiers, 8-848 and imiquimod. Cell Immunol 1999; 191: 10-9.

9 Smits EL, Cools N, Lion E, Van Camp K, Ponsaerts P, Berneman ZN, et al. The Toll-like receptor $7 / 8$ agonist resiquimod greatly increases the immunostimulatory capacity of human acute myeloid leukemia cells. Cancer Immunol Immunother 2010; 59: 35-46.

10. Triantafilou K, Orthopoulos G, Vakakis E, Ahmed MA, Golenbock DT, Lepper PM, et al. Human cardiac inflammatory responses triggered by Coxsackie B viruses are mainly Toll-like receptor (TLR) 8-dependent. Cell Microbiol 2005; 7: 1117-26.

11 Xuan YT, Tang XL, Banerjee S, Takano H, Li RC, Han H, et al. Nuclear factor $\mathrm{B}$ plays an essential role in the genesis of the late phase of ischemia preconditioning in conscious rabbits. Circ Res 1999; 84: 
1095-109.

12 Nicholas SA, Sumbayev VV. The role of redox-dependent mechanisms in the downregulation of ligand-induced Toll-like receptors 7, 8 and 4-mediated HIF1 alpha prolyl hydroxylation. Immunol Cell Biol 2010; 88: $180-6$.

13 Nicholas SA, Sumbayev VV. The involvement of hypoxia-inducible factor 1 alpha in Toll-like receptor 7/8-mediated inflammatory response. Cell Res 2009; 19: 973-83.

14 Natarajan R, Salloum FN, Fisher BJ, Kukreja RC, Fowler AA. Hypoxia inducible factor-1 activation by prolyl 4-hydroxylase-2 gene silencing attenuates myocardial ischemia reperfusion injury. Circ Res 2006; 98: 133-40.

15 Reinecke H, Zhang M, Bartosek T, Charles E. Survival, integration, and differentiation of cardiomyocyte grafts. Circulation 1999; 100: 193-202.

16 Li F, Mahato RI. iNOS gene silencing prevents inflammatory cytokine induced $\beta$-cell apoptosis. Mol Pharm 2008; 5: 407-17.

17 Kenneth JK, Thomas DS. Analysis of relative gene expression data using real-time quantitative PCR and the $2^{-\Delta \Delta \mathrm{Ct}}$ method. Methods 2001; 25: 402-8.

18 Andrews NC, Faller DV. A rapid micropreparation technique for extraction of DNA-binding proteins from limiting numbers of mammalian cells. Nucleic Acid Res 1991; 19: 2499.

19 Leung PY, Packard AE, Stenzel-Poore MP. It's all in the family: multiple Toll-like receptors offer promise as novel therapeutic targets for stroke neuroprotection. Future Neurol 2009; 4: 201-8.

20 Bolli R. Preconditioning: a paradigm shift in the biology of myocardial ischemia. Am J Physiol Heart Circ Physiol 2007; 292: H19-27.

21 Rizvi A, Tang XL, Qiu Y, Xuan YT, Takano H, Jadoon AK, et al. Increased protein synthesis is necessary for the development of late preconditioning against myocardial stunning. Am J Physiol 1999; 277: H87484.

22 Meng X, Cleveland JC Jr, Rowland RT, Mitchell MB, Brown JM, Banerjee A, et al. Norepinephrine-induced sustained myocardial adaptation to ischemia is dependent on alpha 1-adrenoceptors and protein synthesis. J Mol Cell Cardiol 1996; 28: 2017-25.

23 Wang YY, Chen BF, Shen DF, Xue S. Osteopontin protects against cardiac ischemia-reperfusion injury through late preconditioning. Heart Vessels 2009; 24: 116-23.

24 Das DK, Maulik N. Preconditioning protentiates redox signaling and converts death signal into survival signal. Arch Biochem Biophys 2003; 420: 305-11.
25 Baines CP, Goto M, Downey JM. Oxygen radicals released during ischemic preconditioning contribute to cardioprotection in the rabbit myocardium. J Mol Cell Cardiol 1997; 29: 207-16.

26 Dendorfer A, Heidbreder M, Hellwig-Burgel T, Johren O, Qadri F, Dominiak P. Deferoxamine induces prolonged cardiac preconditioning via accumulation of oxygen radicals. Free Radic Biol Med 2005; 38 : 117-24.

27 Frantz S, Ertl G, Bauersachs J. Mechanisms of disease: Toll-like receptors in cardiovascular disease. Nat Clin Pract Cardiovasc Med 2007; 4: 444-54.

28 Bergeron M, Gidday JM, Yu AY, Semenza GL, Ferriero DM, Sharp FR. Hypoxia-inducible factor 1 (HIF-1) role in hypoxia-induced ischemic tolerance in neonatal rat brain. Ann Neurol 2000; 48: 285-96.

29 Jung F, Palmer LA, Zhou N, Johns RA. Hypoxic regulation of inducible nitric oxide synthase via hypoxia inducible factor-1 in cardiac myocytes. Circ Res 2000; 86: 319-25.

30 Belaidi E, Beguin PC, Levy P, Ribuot C, Godin-Ribuot D. Prevention of HIF-1 activation and iNOS gene targeting by low-dose cadmium results in loss of myocardial hypoxic preconditioning in the rat. Am J Physiol Heart Circ Physiol 2008; 294: H901-8.

31 Xi L, Taher M, Yin C, Salloum F, Kukreja RC. Cobalt chloride induces delayed cardiac preconditioning in mice through selective activation of HIF1 $\alpha$ and AP-1 and iNOS signaling. Am J Physiol Heart Circ Physiol 2004; 287: H2369-75.

32 Zhao TC, Taher MM, Valerie KC, Kukreja RC. P38 triggers late preconditioning elicited by anisomycin in heart: involvement of NFKB and iNOS. Circ Res 2001; 89: 915-22.

33 Jones SP, Bolli R. The ubiquitous role of nitric oxide in cardioprotection. J Mol Cell Cardiol 2006; 40: 16-23.

34 West MB, Rokosh G, Obal D, Velayutham M, Xuan YT, Hill BG, et al. Cardiac myocyte-specific expression of inducible nitric oxide synthase protects against ischemia/reperfusion injury by preventing mitochondrial permeability transition. Circulation 2008; 118: 19708.

35 Forsbach A, Nemorin JG, Montino C, Müller C, Samulowitz U, Vicari AP, et al. Identification of RNA sequence motifs stimulating sequencespecific TLR8-dependent immune responses. J Immunol 2008; 180: 3729-38.

36 Goodchild A, Nopper N, King A, Doan T, Tanudji M, Arndt GM, et al. Sequence determinants of innate immune activation by short interfering RNAs. BMC Immunol 2009; 10: 40. 